\title{
Capacidade estatal e formulação de políticas sociais por municípios sob a ótica da gestão pública democrática
}

\author{
Marília Della Lucia Gomes \\ Mestre em Administração Pública (Universidade Federal de Lavras) \\ Professora do Centro Universitário de Lavras \\ Lavras, Brasil \\ mdellalucia@hotmail.com \\ Patrícia Aparecida Ferreira \\ Doutora em Administração (Universidade Federal de Lavras) \\ Professora da Universidade Federal de Lavras \\ Lavras, Brasil \\ paf@dae.ufla.br \\ Júlia Moretto Amâncio \\ Doutora em Ciência Sociais (Unicamp) \\ Professora da Universidade Federal de Lavras \\ Lavras, Brasil \\ jumorettoamancio@gmail.com
}

A Constituição Federal de 1988 alargou as responsabilidades do Estado Democrático Brasileiro ao estabelecer atividades prestacionais ao cidadão, em termos de direitos sociais, os quais são efetivados por meio das políticas públicas. Ao mesmo tempo, operou a municipalização de alguns serviços sociais universais e gerou novas institucionalidades na governança local, pois distribuiu competências e reconheceu a autonomia dos municípios, lugar de execução e de disponibilização de serviços públicos e de elaboração de políticas públicas condizentes com as necessidades da população local. Este trabalho tem o objetivo de promover uma discussão teórica e trazer à baila os estudos sobre as capacidades estatais, propondo que sejam adaptadas de forma a aplicarem-se aos municípios, visando impulsionar a capacidade de formulação de suas políticas sociais, bem como contribuir com as discussões sobre capacidades estatais a nível local integrando, para tanto, o referencial da gestão pública democrática.

Palavras-chave: capacidade estatal, formulação, políticas sociais, gestão pública democrática, descentralização, municipalização. 


\section{Introdução}

Com a promulgação da Constituição Federal de 1988 (CF/88), que reiterou o reconhecimento dos direitos sociais como fundamentais e universais e os delegou ao provimento do Estado, ganhou maior espaço e relevância a discussão sobre as políticas sociais, suas especificidades e a necessidade de garantir que os governos as formulem e as gerenciem de forma a atender o interesse público e garantir uma cidadania plena. Ao mesmo tempo, viu-se, no Brasil, uma reforma constitucional que operou a descentralização político-administrativa, por meio de um pacto federativo sui generis, com a elevação do Município à condição de ente federado, o que concedeu autonomia e "empoderou" os governos municipais, delegando a eles várias obrigações no sentido da execução de políticas de cunho social. Na perspectiva política, tratou-se de um processo de redemocratização das estruturas de poder, de modo a transferir até a esfera local de governo as políticas sociais, onde elas poderiam ser mais bem submetidas ao controle social (Arretche, 2000).

Apesar do reconhecimento da importância do campo das políticas sociais, ainda é parcial a promoção do desenvolvimento econômico juntamente à promoção da inclusão social e à garantia dos direitos sociais para grande parte da população (Souza, 2006), de forma ampla igualitária e emancipadora. Destaca-se que a efetivação dos direitos sociais depende, muitas vezes, da capacidade dos municípios para a formulação de políticas, pois nessa fase é possível planejar e desenhá-las, de modo que a elaboração atenda de forma mais próxima às reais necessidades da população local. Esse acúmulo de competências do município reflete na formulação de políticas, programas e planos nacionais, assim como na constituição de sistemas únicos, em que se busca a integração das ações dos diferentes entes governamentais. Esses programas, planos e sistemas, em sua maioria, estruturam-se em políticas nacionais baseadas em princípios de transferência de recursos e descentralização de ações coordenadas pelo governo federal, exigindo-se, no entanto, contrapartidas dos entes. Através desta dinâmica, a configuração do federalismo brasileiro incentivou que estados e municípios participassem diretamente da implementação de políticas originalmente executadas pelo governo central, como é o caso da saúde e da educação (Lotta; Gonçalves; Bitelman, 2014).

As discussões acerca do federalismo brasileiro têm demonstrado a predominância da coordenação de políticas sociais, impulsionada pelas diretrizes da União. Assim, o impasse entre formulação versus implementação de políticas sociais nos municípios permeia a discussão de capacidades estatais, uma vez que as próprias reformas de descentralização x centralização foram fundamentadas em razão das disparidades locais quanto à capacidade de respostas às demandas locais.

Lotta, Gonçalves e Bitelman (2014), baseando-se em Souza e Carvalho (1999), afirmam que estas disparidades existentes no país se refletem em significativas diferenças nas condições financeiras, institucionais, políticas e técnico-administrativas dos entes subnacionais, o que interfere em sua capacidade de resposta às necessidades e demandas da po- 
pulação. $\mathrm{Na}$ esfera local, tais distinções revelam que a maioria dos municípios brasileiros, de menor porte, depende profundamente do governo federal e dos governos estaduais.

Dentro desta perspectiva, a elaboração e a implementação de políticas sociais ganharam maior visibilidade acadêmica, sobretudo, o estudo sobre as questões federativas que as envolvem, tendo em vista que, em tese, essas políticas possuem maior eficácia, se baseadas nas relações específicas de uma determinada população, o que pode ser feito de forma mais efetiva em âmbito municipal. Embora os governos locais tenham papel de destaque, a formulação e a execução de políticas sociais têm sido marcadas pela forte regulamentação federal, principalmente, quando limitam a autonomia decisória dos municípios com relação à alocação de recursos (Arretche, 2010).

Portanto, a autonomia dos municípios para decisão pode não significar apenas em capacidade de utilização de discricionariedade para formulação de políticas sociais locais, mas na elaboração de ações, planos, programas visando à implementação das políticas desenhadas em âmbito federal.

Assim, a importante posição jurídica do município brasileiro se contrapõe a sua capacidade bastante limitada de atuação prática. Por esta razão, especialmente no momento da formulação de políticas públicas, é comum a constante reprodução da legislação federal ou estadual em âmbito local. Essa prática tem sido criticada devido à insegurança e ao comodismo de legisladores e servidores municipais e, também, pela incapacidade técnica de promoverem inovações legislativas em programas municipais (Andrade, 2004).

Surge, pois, a necessidade de realizarem-se estudos que procurem colaborar com o desenvolvimento da dinâmica de elaboração de políticas sociais por municípios, em contraposição à realidade estritamente centralizadora verificada historicamente no Brasil e a limitação em termos técnicos e financeiros, devido, sobretudo, às heterogeneidades municipais, à baixa capacidade técnica de seus agentes públicos, ao predomínio de relações clientelistas e aos parcos recursos financeiros enfrentados pelos entes municipais.

O trabalho tem como objetivo promover uma discussão teórica e trazer à baila os estudos sobre as capacidades estatais, propondo que elas sejam aplicadas nos municípios no momento da formulação de suas políticas de sociais, considerando as dimensões da gestão pública democrática propostas por Paes de Paula (2005).

Levando-se em conta que o conceito de capacidades estatais refere-se aos recursos (administrativos, financeiros, políticos etc.) disponíveis para moldar as intervenções estatais (pierson, 1995) de forma a alcançar maior eficiência e eficácia para atingir objetivos em políticas públicas, parte-se do pressuposto de que, para que se demonstre capacidade estatal para a formulação de políticas locais, o município deve basear-se na construção de uma gestão pública democrática, a qual passa pela análise e desenvolvimento de três dimensões fundamentais:

1) a dimensão econômico-financeira, que se relaciona com os problemas do âmbito das finanças públicas e investimentos estatais, envolvendo questões de natureza fiscal, tributária e monetária; 2) a dimensão institucional-administrativa, que abrange os problemas de organização e articulação dos órgãos que 
compõem o aparato estatal, como as dificuldades de planejamento, direção e controle das ações estatais, e a questão da profissionalização dos servidores públicos para o desempenho de suas funções; 3) a dimensão sociopolítica, que compreende problemas situados no âmago das relações entre o Estado e a sociedade, envolvendo os direitos dos cidadãos e sua participação na gestão (Paes de Paula, 2005, p. 40).

Assim, considera-se que, quanto mais próximo de uma gestão pública democrática, ou seja, quanto melhor o município souber trabalhar e resolver os problemas relativos às dimensões citadas, maior será a sua capacidade de formulação de políticas locais. E ainda que o conceito de capacidades estatais denote, inicialmente, a ideia de se tratar da análise das capacidades de um Estado como um todo, como um ente soberano, os estudos atuais, também têm utilizado este conceito para análise de políticas públicas de entes federados, no caso do Brasil, estados e municípios.

Após esta introdução, a primeira seção fará uma abordagem geral sobre políticas sociais e suas acepções. A segunda seção se aterá ao tema das capacidades estatais e sua relação com a formulação de políticas sociais e apresentará, nas subseções, as dimensões da gestão pública democrática que devem ser desenvolvidas pelos municípios para a efetivação da formulação de políticas sociais eficientes, quais sejam, a dimensão institucionaladministrativa, a econômico-financeira e a sociopolítica. Depois, serão apresentadas as conclusões e apresentas as referências bibliográficas.

\section{Abordagens gerais sobre políticas sociais}

Embora os autores não apresentem um conceito único sobre políticas sociais, não se pode deixar de considerá-las como políticas públicas. Segundo Abranches, Santos e Coimbra (1998), a política social se relaciona com o processo estatal de alocação e distribuição de valores. Assim, a política social é reconhecida como a ação governamental com objetivos relacionados à proteção social, ou seja, são as políticas públicas referidas àquelas ações que exercem - pelo menos em tese - um impacto direto sobre o bem-estar dos cidadãos.

Conforme esclarece Gomez (2012), as políticas públicas são dispositivos utilizados para controle social, definidos pelos sistemas políticos modernos, com o propósito de regulamentar um assunto de interesse público, bem como a forma de aplicação dos recursos. Para o autor, nas sociedades em que predomina o Estado de Direito, as políticas públicas podem ser definidas como diretrizes obrigatórias firmadas com o propósito de regular um assunto considerado de interesse público.

Souza (2007) afirma que a política pública, em geral, e a políticas sociais em particular, são campos multidisciplinares, mas reconhece que, poucas vezes, temos clareza de que existem distinções importantes entre o estudo destas políticas, cada qual detém um foco diferente. Assim, as pesquisas sobre as políticas sociais expandiram-se através dos primeiros estudos sobre o Estado do bem-estar social e atualmente abrangem áreas como: política e gestão de serviços sociais, problemas sociais diversos e grupos sociais minoritários e excluí- 
dos (Souza, 2007).Em termos de provisão, as políticas sociais podem ser de acesso universal ou focalizado, neste caso, podendo ser direcionadas para determinados grupos sociais.

Por sua vez, Arretche (2010) classifica as políticas sociais descentralizadas em dois tipos: a) Políticas sociais reguladas, que são aquelas em que a autonomia decisória dos governos dos entes da federação é limitada pelo estabelecimento de limites de gasto e de modalidades de execução das políticas; b) Políticas sociais não reguladas, que são caracterizadas pela autonomia dos entes federados descentralizados para tomar decisões (policy decision-making) acerca da execução das políticas (policy-making).

O sucesso de uma política social, em termos de atendimento de sua finalidade social, não depende somente das escolhas das alternativas de solução dos problemas enfrentados, é preciso, acima de tudo, possibilitar que as ações planejadas sejam colocadas em prática de modo efetivo. Isso porque a política social é uma área por excelência para discussão dos conflitos inerentes a todas as formas de desigualdade e exclusão.

Conclui-se, pois, que as políticas sociais são a forma de efetivação das promessas e direitos garantidos pelo Estado ao cidadão. Num estado federativo, como é o caso brasileiro, caracterizado pela forte descentralização político-administrativa, esta efetivação fica a cargo dos entes federados, de acordo com suas competências constitucionais e autonomias. Conforme Lobato (2006), nos últimos vinte anos, o Brasil tem feito esforços importantes para mudar o padrão tradicional de tratamento dos problemas sociais e construir uma nova institucionalidade para a questão social. Para atingir esse objetivo, o desenvolvimento das capacidades estatais, nos termos aqui propostos, pode representar avanços positivos.

\section{Capacidades estatais e a formulação de políticas sociais}

A noção de capacidades estatais foi desenvolvida para explicar por que alguns Estados possuem maior eficácia e eficiência em prover bens públicos, no sentido de estabelecer objetivos e cumpri-los, de forma a impulsionar e direcionar o desenvolvimento socioeconômico ou alcançar objetivos determinados em políticas específicas (Boschi; Gaitán, 2012; Gomide; Pires, 2014; Stein, 2015). Sob a perspectiva teórica da "autonomia relativa do Estado"1 (Souza, 2007), discutida no âmbito do neoinstitucionalismo histórico, a análise das capacidades estatais busca evidenciar o que faz com que os governos tenham sua atuação permeada por influências externas e internas, as quais geram capacidades ou incapacidades, criando ou não condições para a formulação e implementação de políticas. De acordo com Souza (2015), o conceito de capacidade estatal foi objeto de tratamento teórico e empírico, com diferentes abordagens e rótulos, por diversos autores, como Mann (1984), Tilly (1981), Skocpol (1979; 1985), Skocpol e Finegold (1982), Evans, Rueschemeyer e Skocpol (1985), Chubb e Peterson (1989), Geddes (1994) e Grindle (1997; 2007; 2012).

1 Nicos Poulantzas foi o principal autor a defender a autonomia relativa do Estado ao declarar que o Estado não é uma “entidade" essencialmente instrumental da classe dominante, mas uma relação ou uma condensação das relações de classe (Bresser-Pereira, 2010). 
Segundo Cingolani (2013), essa é uma noção inacabada, um conceito ainda em construção e um campo a ser definido. Para chegar à conclusão, a autora faz uma revisão do conceito baseada em vários autores e cita algumas contribuições como as dos seguintes autores: (1) Charles Tilly (1975), apontado pela autora como precursor do conceito, afirma ser a capacidade estatal (ou stateness) o poder do Estado para estimar os recursos necessários à população local e para vencer a resistência da população para combater à captação recursos decorrentes. (2) Skocpol (1985) que define capacidade estatal como habilidade para implementar objetivos oficiais, mesmo que em oposição ao poder/resistência de grupos sociais ou em face de circunstâncias socioeconômicas não favoráveis. (3) Evans and Rauch (1999 a 2000), por meio de um estudo empírico que avalia o efeito das dimensões da burocracia weberiana no desenvolvimento econômico. (4) Dincecco (2011) conceitua capacidade estatal como a combinação de centralização na captação de recursos e a limitação do poder executivo por mecanismos de freios e contrapesos institucionais.

Por sua vez, Pierson (1995) defende que as capacidades estatais estejam ligadas aos recursos administrativos e financeiros disponíveis para adaptar intervenções de políticas. Por ser um conceito flexível, permite explorar diferentes aspectos da ação estatal e da relação das estruturas estatais com a sociedade e com o sistema econômico (Stein, 2015), incorporando variáveis políticas, institucionais, administrativas e técnicas (Souza, 2015).

Desse modo, o conceito vem adquirindo centralidade nas pesquisas das áreas de Ciência Política e Administração Pública sobre boa governança ou governança e crescimento, uma vez que os estudos sobre capacidades estatais têm se direcionado a verificar os atributos que os Estados devem possuir para atingir, de forma efetiva, os objetivos que pretendem por meio de suas políticas públicas, como a provisão de bens e serviços públicos (Gomide; Silva; Pires, 2014). Nesse sentido, o conceito se relaciona aos atributos que caracterizam o Estado em ação, possibilitando "a identificação de problemas, a formulação de soluções, a execução de ações e a entrega dos resultados -, processo que envolve atores, instrumentos e processos que, coordenados, resultam em políticas públicas de desenvolvimento" (Evans, 1995; Geddes, 1996; Skocpol, 1985; Skocpol; Finegold, 1982; Mann, 1993, p. 236).

Por outro lado, segundo o Instituto Sul-Americano de Política e Estratégia (ISAPE) (2012), ao longo dos últimos anos, na América do Sul, tornou-se evidente a comprovação de que a capacidade de um Estado é condição para a democracia. Neste sentido, torna-se importante o estudo dos problemas associados à construção de capacidades institucionais e do fortalecimento do Estado, pois, o regime democrático demonstra-se inócuo, se não houver capacidade para implementar as decisões tomadas pelos sujeitos políticos ou para garantir o cumprimento dos direitos e deveres associados à cidadania (ISAPE, 2012, p. 1).

No que se refere à capacidade estatal no campo da gestão de políticas públicas, conforme exposto por Souza (2010) apud Bichir (2011), a capacidade de formular e implementar políticas integra a modernização do Estado e a efetividade da ação do Estado. 
envolvem na formulação de políticas públicas e no seu processo, tais como grupos de interesse e os movimentos sociais, cada qual com maior ou menor influência a depender do tipo de política formulada e das coalizões que integram o governo, e apesar de uma certa literatura argumentar que o papel dos governos tem sido encolhido por fenômenos como a globalização, a diminuição da capacidade dos governos de intervir, formular políticas públicas e de governar não está empiricamente comprovada.Visões menos ideologizadas defendem que apesar da existência de limitações e constrangimentos, estes não inibem a capacidade das instituições governamentais de governar a sociedade $[. .$.$] apesar de tornarem a atividade de governar e formular políti-$ cas públicas mais complexa (Souza, 2007, p. 72).

Ao abordar acerca das dimensões ou indicadores necessários para a demonstração da capacidade de formulação de políticas, Souza (2010) apresenta as diferenças entre as capacidades necessárias para a formulação e aprovação de políticas e para a implementação destas políticas. No primeiro caso, são elencadas as capacidades informacionais, desenho das políticas e suas regras, maioria legislativa, conciliação da política pública com os interesses privados, políticas prévias e informações sobre políticas semelhantes. No segundo, as capacidades financeiras, infraestruturais (referentes principalmente à burocracia) e alcance territorial (capilaridade das políticas) (Bichir, 2011).

Nota-se que o conceito de capacidade do Estado de Souza (2010) incorpora dimensões políticas, institucionais, administrativas e técnicas, ressalvando que "o enfoque das capacidades estatais não implica assumir que as políticas foram bem sucedidas em seus resultados, mas sim avaliar a capacidade de provisão das políticas" (Souza, 2010, p. 4).

Como já explicitado acima, embora o conceito de capacidades estatais, conforme desenhado originalmente, faça inferir, a priori, a existência de atributos de um Estado como um todo, que o faz atingir de forma efetiva os seus objetivos, este conceito tem se mostrado bastante propício para análise de entes federados autônomos, como no caso dos estados e municípios brasileiros.

O que se percebe é que o desafio atual no contexto brasileiro (e, possivelmente, na América Latina) é aumentar a eficiência e eficácia das políticas, ou melhor, a qualidade dos serviços públicos (Gomes, 2010).

Entretanto, podem ser identificados vários problemas que comprometem a eficiência e eficácia das políticas e que estão, de alguma forma, relacionados com um projeto institucional inadequado. Dentre os problemas, citam-se as disparidades regionais, a baixa capacidade de resposta do governo às necessidades sociais e o comportamento fiscal irresponsável dos governos.

Assim, o próprio processo de formulação de políticas públicas é resultado da relação entre a atuação das burocracias do Poder Executivo e os mecanismos de controle e participação política, ou seja, dos arranjos institucionais em torno dessa determinada política. Conforme destaca Gomide e Pires (2014), os arranjos institucionais correspondem 
a uma série de regras específicas que os agentes constituem nas suas relações políticas e sociais particulares, ou seja, eles determinam a forma de coordenação de processos em determinados campos, ao balizar aqueles que se encontram habilitados a participar de tais processos, os objetos e os seus objetivos, bem como as formas de relações entre os atores.

Tais autores destacam que são os arranjos institucionais que garantem ao Estado a capacidade de execução de seus objetivos e que, no contexto democrático, essa capacidade é percebida por meio de dois componentes: o técnico-administrativo e o político. $\mathrm{O}$ primeiro componente é advindo do conceito de burocracia weberiana e o segundo está ligado à capacidade da burocracia do Executivo de expansão de canais de interlocução com os atores sociais (Gomide; Pires, 2014).

Portanto, na fase da formulação de uma política social, baseada na gestão pública democrática, que atenda aos princípios de participação e de cidadania descritos na CF/88, devem ser identificadas três dimensões fundamentais: a dimensão econômico-financeira, a dimensão institucional-administrativa e a dimensão sociopolítica (Paes de Paula, 2005). A autora reconhece que a ênfase em cada uma destas dimensões depende da vertente paradigmática da administração pública, uma vez que, na vertente gerencial, a ênfase recai principalmente nas dimensões econômico-financeira e institucional-administrativa e, na vertente societal, a ênfase está na dimensão sociopolítica.

A vertente gerencial, que está imbricada com o projeto político do ajuste estrutural e do gerencialismo, baseia-se nas recomendações dessas correntes para reorganizar o aparelho do Estado e reestruturar a sua gestão, focalizando as questões administrativas. A vertente societal, por sua vez, enfatiza principalmente a participação social e procura estruturar um projeto político que repense o modelo de desenvolvimento brasileiro, a estrutura do aparelho de Estado e o paradigma de gestão.

O fato de cada uma das vertentes ocuparem um dos extremos do debate reflete a clássica dicotomia entre a política e a administração que circunda a gestão pública.

Além disso, a análise realizada revelou que a vertente societal não tem propostas completamente acabadas para as dimensões econômico-financeira e institucional-administrativa, e que a vertente gerencial lida com a dimensão sociopolítica predominantemente no âmbito do discurso (Paes de Paula, 2005, p. 41).

Neste sentido, defende-se que, para que o Município demonstre capacidade estatal de formulação de políticas sociais baseadas em cânones democráticos, a administração pública deve balizar suas ações no paradigma gerencial, no que se refere à dimensão econômico-financeira e institucional-administrativa, e no paradigma societal, no que se refere à dimensão sociopolítica.

Nas Subseções seguintes, apresentam-se os principais aspectos de cada uma das dimensões da gestão pública democrática, consideradas desenvolvimento das capacidades estatais dos entes federados, no caso deste trabalho, dos municípios. 


\subsection{Dimensão institucional-administrativa}

Ao se estudar a formulação de políticas sociais, não há como não pensar nos arranjos institucionais que dão sustentação aos processos decisórios e que abarcam as relações das instituições políticas com os requisitos jurídico-organizacionais necessários à constituição de capacidades técnico-administrativas. Esses arranjos dizem respeito à forma como são organizados administrativamente o ente federativo, os instrumentos legais que deve respeitar, além dos mecanismos de coordenação, de transparência, de prestação de contas e de controle. Portanto, as características da dimensão institucional-administrativa são evidenciadas pelas determinações legais, normas administrativas editadas em cada área de política pública e nos padrões históricos de organização político-administrativa e de relações dos gestores públicos com os grupos sociais cujos interesses estão afetos à área (Côrtes, 2007).

Outros aspectos importantes da dimensão institucional-administrativa dizem respeito à accountability horizontal, ligada à interação entre executivo e legislativo e à atuação de instituições de controle (judiciário, tribunais de contas, ministério público, órgãos investigativos), assim como a promoção de ações transparentes frente à sociedade. Segundo Evans (2011), a capacidade técnico-administrativa está associada à competência da burocracia estatal em traçar, implementar e coordenar estratégias, nos diferentes níveis de governo, visando à coordenação interorganizacional e interfederativa, além do planejamento de médio e longo prazo e da execução orçamentária.

Assim, o fator institucional que pode interferir na capacidade de resposta dos governos às necessidades públicas, de forma eficiente e efetiva, está ligado às capacidades administrativas. Especialmente no que se refere às disparidades com relação a essas capacidades entre os governos, as desigualdades existentes no país se refletem em significativas diferenças nas condições financeiras, institucionais, políticas e técnico-administrativas dos entes subnacionais. Tais diferenças, segundo Souza e Carvalho (1999 apud Lotta, Gonçalves e Bitelmam, 2014), interferem na capacidade de resposta dos entes às necessidades e demandas da população, sobretudo na esfera local. Essa constatação corrobora com o posicionamento de Arretche (2000), no sentido de que um dos fatores determinantes para o sucesso do processo de descentralização, assim como a situação econômica financeira do ente federado, é a capacidade administrativa do ente.

Para alcançar este desiderato, os servidores públicos são atores centrais no processo de decisão política, vez que podem influenciar a formulação de políticas sociais em suas áreas específicas de governo, pois, apesar de aparentemente serem agentes impessoais, que apenas cumprem ordens politicamente neutras, podem efetivamente tomar decisões, tendo em vista as informações e meios essenciais para a implementação das políticas sociais que detêm (Cortês, 2007). No entendimento de Cortês (2007), no que se refere a uma gestão pública mais democrática, o poder dos servidores públicos pode aumentar à medida que assumem cargos de direção na gestão pública. Isso porque, dependendo de suas posições político- ideológicas, eles podem promover diferentes tipos de participação 
ao dirigirem fóruns ou na decisão sobre a infraestrutura de apoio a ser colocada à disposição dos conselhos gestores de políticas sociais e na sua dinâmica de funcionamento; na possibilidade de fazer cumprir as decisões ali tomadas; na possibilidade de pressionar os gestores e provedores de serviços, benefícios e bens para o cumprimento dessas decisões. Nas áreas da saúde e da assistência social, por exemplo, havendo descentralização, os serviços do município financiados com recursos públicos, estarão sob o comando destes servidores (Côrtes, 2007). Assim, "profissionais, servidores públicos localizados em postos de comando, ministros, secretários e mais recentemente policy communities são muito influentes em processo de tomada de decisões que ocorre em um contexto de policy networks" (Côrtes, 2007, p. 133).

Entretanto, no que se refere à administração pública local, existe um grave e evidente problema que, muitas vezes, reverte-se em entrave à atuação de servidores públicos, que é a baixa qualificação das burocracias municipais, que não são capazes de prover, de forma adequada, bens e serviços públicos que antes eram de responsabilidade dos entes centrais de governo e que foram descentralizados (Thomaz; Cunha, 2014). Ainda é corrente, principalmente em âmbito local, a preterição de políticas públicas planejadas, de interesse público, em função de práticas clientelistas e antidemocráticas (Iizuka, 2013; Oliveira, 2006). Uma forma de resolver o problema, conforme já previa Arretche (2000), é desenvolver políticas de capacitação municipal, principalmente a qualificação de servidores públicos, pois, como ressalta Souza (1996), não faltam aos municípios somente a capacidade de reinventar o governo, mas também as condições mínimas para o exercício do próprio governo.

Nesse sentido, está o posicionamento de Prud'Homme (1995), para quem os problemas ligados à capacidade administrativa local acarretam um potencial entrave à formulação de políticas de forma eficiente e responsável. Para o autor, esses problemas podem estar relacionados, por exemplo, às dificuldades de atração de pessoal qualificado para as administrações locais, tendo em vista que os governos centrais tendem a oferecer melhores remunerações, bem como melhores perspectivas de desenvolvimento na carreira, mobilidade, dentre outros.

Conforme constata Gomes (2010), para fazer face às necessidades de formulação de políticas sociais locais, os municípios precisam avaliar e adequar suas estruturas administrativas, capacitar-se técnica e financeiramente e ampliar o relacionamento com o setor privado e com organizações da sociedade civil. Tudo isso somente é possível, se os governos locais souberem desenvolver adequadamente suas estruturas institucionais e administrativas, de forma a dar respostas às necessidades da população local.

\subsection{Dimensão econômico-financeira}

As três categorias de autonomia do ente municipal (política, administrativa e financeira) tratadas na Constituição não devem ser consideradas de forma separada. Isso, porque a autonomia política, a descentralização administrativa ou mesmo a cidadania participativa não são suficientes para levar à agenda pública local os interesses da comuni- 
dade, se não se forneçam todas as condições para que os poderes locais possam concretizar políticas públicas eficientes e eficazes. Junto das autonomias, administrativa e política, há que se consolidar a autonomia financeira dos poderes locais, vez que ambas necessitam de recursos para custear as atividades municipais. Caso contrário, acarretam a dependência dos municípios com relação aos demais entes federados, perdendo a razão de ser da descentralização instituída pela Constituição Federal (Antinarelli, 2012). Nesse sentido, a autonomia financeira é considerada um fator fundamental para a operacionalização das políticas públicas dos governos locais, pois, se não há recursos financeiros, os governos não serão capazes de agir. Assim, a capacidade fiscal dos governos subnacionais é determinante, ou seja, do ponto de vista da formulação teórica do federalismo, a autonomia fiscal seria um mecanismo fundamental para garantir a alocação eficiente dos recursos, de forma que possa responder às demandas dos cidadãos (Gomes, 2010).

A Carta Constitucional de 1988, seguindo uma evolução histórica que vinha acontecendo desde a Constituição Federal de 1891, e passou a implementar a separação de fontes tributárias e discriminação de impostos de competência exclusiva entre os entes federados ${ }^{2}$, trouxe um novo sistema de financiamento do estado, com uma divisão maior de recursos e maior autonomia fiscal para os entes subnacionais, ou seja, Estados e Municípios (Arretche, 2004; Thomaz; Cunha, 2014). Entretanto, a arrecadação de tributos ainda é desigual, muito em função das competências tributárias de cada um dos entes federativos, como uma concentração desta na União.

No que tange à distribuição de receitas federais, pode-se dizer que há três formas diferentes de participação dos Estados, do Distrito Federal e dos Municípios nas receitas obtidas pela União. A primeira ocorre com participação direta no produto da arrecadação de determinados impostos (art. 157, I e 158, I, da CF/88); a segunda se dá com a participação partilhada direta no produto de determinado tributo (art. 157, II; 158, II, III, e IV; e 159, III, CF/88); e a terceira, que é a participação indireta por meio de fundos formados por uma parcela de determinadas exações (art. 159, I, da CF/88) (Brasil, 2002). A receita tributária dos municípios é composta de receitas próprias (arrecadadas por meio de atividade direta do ente), impróprias (provenientes de transferências constitucionais e voluntárias da União e dos Estados, através de fundos de participação ou de impostos que são de competência dos demais entes federados) e pelas transferências condicionadas universais (vinculadas a políticas setoriais) (Arretche, 2010). Dentre as receitas próprias estão as provenientes da arrecadação do Imposto Predial Territorial Urbano (IPTU), do Imposto sobre Transmissão Inter-Vivos (ITBI) e do Imposto sobre Serviços de Qualquer Natureza (ISS), além das taxas, contribuições de melhoria e preços públicos.

Dentre as transferências constitucionais federais, a mais importante é o Fundo de Participação dos Municípios (FPM), que tem orientação redistributiva, embora sua efe-

2 Esta evolução sofreu períodos de rupturas, principalmente durante o regime militar (1965-1968), que impôs na Constituição de 1967, uma alta concentração de poder decisório na esfera federal e que operou uma forte centralização na reforma Tributária de então. 
tividade seja bastante controversa ${ }^{3}$. Este Fundo é composto por $24 \%$ das receitas dos dois principais impostos federais: o Imposto de Renda e o Imposto sobre Produtos Industrializados (IPI). Dez por cento são distribuídos entre as capitais, e os restantes $90 \%$ são distribuídos entre as demais cidades (Brasil, 2002).

As transferências constitucionais estaduais, por outro lado, operam segundo o princípio da devolução tributária. Isto é, os estados devem distribuir para seus próprios municípios com 25\% do total da arrecadação do Imposto sobre a Circulação de Mercadorias e Serviços (ICMS), bem como com 50\% das receitas do Imposto sobre a Propriedade de Veículos Automotores (IPVA). Setenta e cinco por cento do montante a ser distribuído deve ser calculado segundo a arrecadação em cada jurisdição (Antinarelli, 2012). Devem ser destinados, também, pelos Estados aos municípios, 25\% dos 10\% do IPI e 25\% dos $29 \%$ do produto da arrecadação da Contribuição de Intervenção no Domínio Econômico, a Cide-combustíveis, que lhes são destinados pela União.

Com relação às transferências condicionadas universais, podem-se citar as transferências financeiras ligadas à saúde e à educação. Na saúde, por exemplo, as transferências tornaram-se universais, uma vez completado o processo de adesão voluntária ao Sistema Único de Saúde (SUS), iniciado em 1990 e estão vinculadas a ações de saúde, que variam desde o atendimento a serviços básicos até o atendimento hospitalar. São consideradas universais no sentido de que todos os municípios que cumpram os requisitos estabelecidos pelas Normas Operacionais do Ministério da Saúde estão aptos a recebê-las, considerando que quase 100\% dos municípios brasileiros operam segundo as regras do SUS (Arretche, 2010).

Segundo Antinarelli (2012), a maior parte dos municípios, em especial os de pequeno e médio porte, ou seja, aqueles de até 100 mil habitantes possuem uma grande dependência das receitas de transferência. Ademais, o autor ressalta as deficiências do sistema de arrecadação destes municípios, sejam elas humanas ou tecnológicas, que diminuem a eficiência nas cobranças dos tributos pelos poderes locais. Isso tudo gera um acomodamento destes municípios quanto à busca pela receita tributária. Assim, as transferências acabam por exercer um efeito desestimulante do esforço fiscal, muito embora a Lei Complemen$\operatorname{tar} n^{\circ} .101 / 2000$ possua previsão de obrigatoriedade da efetiva arrecadação dos tributos.

Como reflexo disso, verifica-se que dados publicados no Editorial do Caderno de Ceas $(1997$, p. 3) "revelam que a média das receitas diretamente arrecadadas pelas prefeituras no Brasil alcança apenas 15\% dos recursos disponíveis, os 85\% restantes são oriundos de contribuições obrigatórias e voluntárias dos governos estaduais e federal" (Rodrigues, 2007, p. 276).

Antinarelli (2012), ao analisar a questão da arrecadação tributária dos municípios do Estado de Minas Gerais, baseado em dados obtidos junto ao relatório das receitas dos municípios mineiros em 2009, elaborado pela Secretaria do Tesouro Nacional (STN),

3 Os critérios de rateio das transferências do Fundo de Participação dos Estados e do Fundo de Participação dos Municípios são diretamente proporcionais à população e inversamente à renda, resultando em maior participação para os Estados e Municípios mais pobres da federação e pouco representando para os Estados do Sul e do Sudeste. 
demonstra a ineficiência dos municípios menores na arrecadação de tributos, se em comparação com municípios maiores (Quadro 1) ${ }^{4}$.

Quadro 1 - Distribuição per capita dos tributos arrecadados no Estado de Minas Gerais

\begin{tabular}{|c|c|c|c|}
\hline População & $\begin{array}{c}\text { ISS, IPTU, ITBI } \\
\text { Per capita }\end{array}$ & $\begin{array}{c}\text { ISS, IPTU, ITBI/ } \\
\text { Receitas Cor- } \\
\text { rentes }\end{array}$ & $\begin{array}{c}\text { ISS, IPTU, } \\
\text { ITBI/ transfe- } \\
\text { rência de ICMS }\end{array}$ \\
\hline $\begin{array}{c}\text { Acima de } \\
100.000\end{array}$ & $\mathrm{R} \$ 143,55$ & $10 \%$ & $62 \%$ \\
\hline $\begin{array}{c}10.000 \mathrm{e} \\
100.000\end{array}$ & $\mathrm{R} \$ 61,68$ & $5 \%$ & $34 \%$ \\
\hline Até 10.000 & $\mathrm{R} \$ 52,95$ & $3 \%$ & $19 \%$ \\
\hline $\begin{array}{c}100.000 \mathrm{e} \\
300.000\end{array}$ & $\mathrm{R} \$ 123,69$ & $9 \%$ & $55 \%$ \\
\hline
\end{tabular}

*Até 10.000 ha (476 municípios)

$\star$ Entre 10.000 e 100.000 ha (366 municípios)

*Acima de 100.000 ha (27 municípios)

Fonte: Antinarelli (2012, p. 453).

Com isso, verifica-se que a União detém o poder político, econômico e decisório das políticas públicas sob sua tutela. Contudo, os investimentos dos governos subnacionais, principalmente em áreas sociais, são peças fundamentais para entendermos e compreendermos a ação política no Brasil (Rodrigues, 2007).

\subsection{Dimensão sociopolítica}

Além da dimensão institucional-administrativa, outra dimensão da capacidade estatal diz respeito à capacidade sociopolítica do ente. Ao analisar a dimensão sociopolítica, devem-se trazer à discussão as relações entre o Estado e a sociedade na definição e formulação das políticas sociais, envolvendo processos democráticos e participativos de defesa dos direitos pelos cidadãos (Paes de Paula, 2005). Conforme expõe Denhardt (2012), muitos problemas encontrados na implementação das políticas públicas podem ser evitados, ou ao menos minorados, se houver maior interesse dos cidadãos ao formular essas políticas. Isso demanda novas capacidades do Estado, que vão além das necessidades de uma burocracia profissional e coesa, ou seja, das capacidades técnicas e administrativas típicas da burocracia weberiana clássica. Numa democracia, como a brasileira, composta de instituições representativas, participativas e deliberativas, mostra-se importante desen-

4 “Em linhas gerais, partimos de três índices: 1) a arrecadação per capita de tributos próprios, excluindo taxas, CIP e Contribuição Previdenciária Própria; 2) o percentual da arrecadação própria x receitas correntes e 3) o percentual da arrecadação própria x transferência do Imposto sobre Circulação de Mercadorias e Serviços - ICMS (que mede, ainda que em parte, atividade econômica). Classificamos os municípios mineiros, para fins de comparação, por população" (Antinarelli, 2012, p. 453). 
volver as capacidades políticas, para a inclusão de múltiplos atores, para a negociação de interesses e para a construção de consensos (Gomide; Pires, 2014).

Em contextos democráticos, as capacidades sociopolíticas estão ligadas ao fato de que, para se formular objetivos relativamente consensuais e viabilizar a implementação de determinadas políticas, é preciso coordenar interesses de modo a "mitigar conflitos, canalizar informações necessárias à formulação, formular visões de futuro compartilhadas, construir bases de legitimidade para as políticas e atuar de maneira responsiva aos interesses da sociedade" (Stein, 2015, p. 13). Para isso, os arranjos institucionais devem propiciar uma atuação colaborativa entre Administração Pública e sociedade civil, ampliando o alcance, a diversidade e a capilaridade das políticas públicas, diante da enorme complexidade dos problemas sociais. Sob essa ótica, a abertura de espaços para a participação da sociedade civil é fundamental.

De acordo com Gomide e Pires (2014), o desenvolvimento dessa dimensão da capacidade estatal, ao incluir múltiplos atores e propiciar a formação de coalizões políticas, é bastante importante, considerando o contexto de um ambiente institucional caracterizado pela existência de instituições representativas, participativas e de controle (social, burocrático e judicial), o que garante apoio para os objetivos e estratégias a serem assumidos.

Segundo Loureiro, Macário e Guerra (2014), na análise da capacidade política é importante focar nas relações existentes entre a burocracia executora de políticas públicas e outros atores políticos dos governos subnacionais e da sociedade civil organizada (membros de conselhos ou outros colegiados), bem como a "burocracia da área de controle Tribunal de Contas da União (TCU), Ministério Público (MP), Controladoria Geral da União (CGU) - na medida em que a fiscalização acaba também afetando os resultados das políticas" (Loureiro; Macário; Guerra, 2014, p. 118).

A partir da Constituição Federal de 1988, assegurou-se essa abertura aos espaços institucionais de participação, como os conselhos de políticas públicas, as conferências e as audiências públicas, nos quais a sociedade civil se faz representar de forma individual quando exercida por cidadãos, ou de forma institucional, quando por organizações da sociedade civil ou movimentos sociais.

O tema da inserção da participação popular na gestão pública é o cerne dessa mobilização (Grupo de Estudos sobre a Construção Democrática, 1999), e atingiu seu ápice em meados da década de 1980, momento da elaboração da Constituinte, quando diferentes forças políticas ofereciam suas propostas para formular um novo referencial das relações entre Estado e sociedade, cada qual fundamentada na sua visão de como deveria ser a construção da democracia no Brasil (Paes de Paula, 2005, p. 39).

Assim, novas formas de relação entre Estado e sociedade e entre público e privado passaram a ser construídas no âmbito das políticas sociais. Nesse contexto, houve abertura para as parcerias com organizações do terceiro setor. Para Junqueira (2004), essas parcerias geram um deslocamento do poder de decisão que funcionam como uma forma de democratização da gestão por meio da participação. Esta forma de gestão participativa tem 
sido classificada, na área de administração pública, como Gestão Social, cujo conceito encontra-se ainda em fase de construção (Cançado; Pereira;Tenório, 2013), embora se possa reconhecer sua concretização na prática, em especial na gestão democrática e participativa das políticas sociais.

Entretanto, na realidade brasileira, grandes são as dificuldades ou limites para a implementação de experiências participativas, em especial aquelas que promovam a emancipação social. Dentre as razões estão assimetrias como: as desigualdades sociais, as culturas autoritárias, clientelistas e patrimonialistas, as dificuldades no entendimento dos aparatos institucionais, bem como a construção de direitos de cima para baixo (Andrade; Castro; Pereira, 2012). De forma geral, as limitações à construção de uma cidadania, que reforce a dimensão sociopolítica de uma gestão pública democrática no Brasil, têm raízes nas práticas coloniais patrimonialistas, nos aspectos autoritários da cultura nacional e na carência de cultura cívica. A construção histórica, cultural, econômica e social do Brasil, conforme é discutida por Faoro (2000) e Carvalho (2007), bem como por outros estudiosos da cultura e sociedade brasileira como Roberto Da Matta, Darcy Ribeiro, Sérgio Buarque de Holanda, Prado Junior, Gylberto Freyre, Oliveira Vianna, Edson de Oliveira Nunes, Florestan Fernandes, mencionados por Campante (2003), apontam as citadas limitações para o período colonial e suas consequências. Questões características dessa época como patrimonialismo, estamento burocrático, nepotismo, formalismo, hierarquia, favoritismo e baixo caráter republicano, típicas do modelo de administração patrimonialista, permearam e ainda permeiam as relações de poder e dominação de nossa estrutura política e aparato administrativo (Alcantara; Pereira; Silva, 2014).

Não obstante a modernização do Estado, muitas das características do modelo patrimonialista se mantiveram, seja no Estado Burocrático ou no Gerencial e, mesmo na direção da democracia, não possibilitaram a participação efetiva da população (Paes de Paula, 2005). Por outro lado, pode-se perceber uma maior participação e disseminação de mecanismos participativos, como nos conselhos gestores de políticas públicas. Esse fortalecimento da ideia de democracia substantiva passa pela discussão normativa de accountability, em que o cidadão se enxerga como agente de elaboração e, ao mesmo tempo, destinatário das políticas públicas, implementando um modelo de governança democrática, caracterizado por uma responsabilidade estendida entre estado/sociedade.

Com efeito, uma descentralização política efetiva consiste, também, na transferência de autonomia para que a comunidade local possa participar da decisão sobre formas de financiamento de serviços e gastos, assim como para o planejamento dos serviços públicos básicos e cotidianos a serem prestados à população, de forma democrática, especialmente nas áreas de políticas sociais, como educação, saúde, segurança, habitação e obras (Bento, 2003). Dessa forma, a conquista de novos espaços de participação da sociedade civil consolidou-se na construção de descentralização das ações, com maior responsabilidade dos municípios na formulação e na implantação de políticas sociais e na possibilidade de transferência de parcelas de poder do Estado para a sociedade civil organizada. 
Tal paradigma tem feito com que muitos governos locais implementem ou consolidem várias experiências participativas, que vão desde conselhos municipais setoriais voltados para a decisão, participação na gestão e fiscalização de políticas sociais e de pequenas obras públicas, até a incorporação de segmentos sociais marginalizados do processo decisório na alocação de parcela dos recursos orçamentários locais (Souza, 2004). Nesse sentido, Souza (2004) conclui que, apesar do incentivo constitucional-legal para o maior envolvimento dos governos e das comunidades locais na provisão de serviços sociais universais e de bens públicos de uso comum, não há garantias de que estas novas configurações institucionais sobreviverão sem o apoio financeiro e indutor do governo federal e de outros organismos exógenos à governança local.

$\mathrm{O}$ quadro seguinte sintetiza as três dimensões das capacidades estatais discutidas nas subseções acima e as capacidades externadas em cada uma dessas dimensões:

Quadro 2 - Dimensões das capacidades estatais

\begin{tabular}{|c|c|}
\hline DIMENSÃO & CAPACIDADE EXTERNADA \\
\hline Institucional-administrativa & $\begin{array}{c}\text { Capacidade técnica e de ges- } \\
\text { tão, recursos humanos, coor- } \\
\text { denação interorganizacional e } \\
\text { interfederativa, juridicidade }\end{array}$ \\
\hline Econômico-financeira & $\begin{array}{c}\text { Liquidez, autonomia fis- } \\
\text { cal, arrecadação }\end{array}$ \\
\hline Sociopolítica & Legitimidade, participação social \\
\hline
\end{tabular}

Fonte: Elaborado pelas autoras (2016).

A dimensão institucional-administrativa da capacidade estatal externa de forma satisfatória alguns tipos de capacidades ligadas a questões como técnica, gestão e recursos humanos. Nessa dimensão estão, ainda, as capacidades de desenvolver relações de cooperação com organizações não governamentais e com outros entes federativos, visando a atender interesses públicos comuns. $\mathrm{Na}$ dimensão econômico-financeira, as capacidades que devem ser externadas, para que se efetive a capacidade estatal, dizem respeito à autonomia fiscal e de arrecadação tributária, além daquela relativa à liquidez para o cumprimento das obrigações assumidas. Por fim, a dimensão sociopolítica deve exteriorizar a capacidade estatal de produzir políticas públicas dotadas de legitimidade democrática, em termos de participação social.

Com base nessas premissas, é possível avançar para um comparativo entre as dimensões das capacidades estatais trabalhadas acima e os desafios a serem enfrentados pelos municípios em cada uma destas dimensões para que estes possam formular políticas públicas democráticas, eficientes e efetivas, como se apresenta no quadro abaixo: 
Quadro 3 - Dimensões das capacidades estatais e os desafios para a gestão municipal

\begin{tabular}{|c|c|}
\hline DIMENSÃO & DESAFIOS PARA A GES- \\
& TÃO MUNICIPAL \\
\hline \multirow{3}{*}{ Institucional-administrativa } & Baixa capacidade técnica \\
& Necessidade de atração de pro- \\
fissionais qualificados \\
Dificuldades no entendimen- \\
to dos aparatos institucionais \\
Deficiências no planejamento e \\
na coordenação interferativa \\
\hline Arrecadação de tributos con- \\
centrados na União \\
& Deficiências nos sistemas de ar- \\
& recadação municipais \\
\hline Sociopolítica & Desigualdades sociais, \\
& Culturas autoritárias, cliente- \\
& listas e patrimonialistas, \\
& Carência de cultura cívica \\
\hline
\end{tabular}

Fonte: Elaborado pelas autoras (2017).

\section{Conclusão}

O presente trabalho visou acrescentar, em termos teóricos, elementos à recente e importante discussão acadêmica acerca das capacidades estatais. Para tanto, foram abordadas discussões sobre as capacidades estatais para a formulação de políticas sociais e se propôs que elas sejam trabalhadas sob a ótica das dimensões da gestão pública democrática de Paes de Paula (2005), quais sejam: a dimensão institucional administrativa, a dimensão econômica financeira e a dimensão sociopolítica.

Focou-se o trabalho na formulação de políticas sociais por municípios, considerando os desafios enfrentados pelas cidades, a partir da descentralização e municipalização de políticas sociais. Portanto, conclui-se que é preciso enfrentar os desafios institucionais e administrativos, que pressupõem e implicam formar servidores competentes tecnicamente, comprometidos politicamente e sensibilizados com os valores que animam o debate sobre a formulação de políticas sociais locais. Outro desafio está em tornar a gestão e o controle institucional, inclusive, o burocrático, mais consistentes, efetivos e profissionalizados, de forma que possam auxiliar na ampliação da capacidade do município de prover suas políticas sociais. Por fim, a gestão democrática exige um esforço do poder público no sentido de implantação de processos decisórios transparentes e que garantam espaço para diálogo entre os grupos sociais no momento de discussão de políticas públicas. 
A construção de uma política pública, que compatibilize os direitos e interesses dos cidadãos, muitas vezes conflitantes, parte do pressuposto de que a governança não se esgota no Estado, necessita agregar as ideias da sociedade e a consciência da escassez de recursos, a fim de conduzir as escolhas para um consenso responsável. Porém, ainda temos um longo caminho a percorrer, a fim de retirar das práticas decisórias as políticas baseadas em paradigmas corporativistas e clientelistas que ocorrem no país, as quais, muitas vezes, acabam por impedir o desenvolvimento de políticas devidamente planejadas de forma técnica e eficiente. Superar este entrave é um desafio, em especial ao desenvolvimento de políticas sociais efetivas, que sejam garantidoras de direitos e que promovam a cidadania, de forma a possibilitar uma relação entre Estado e sociedade capaz de garantir aos cidadãos acesso a seus interesses e sua defesa de forma mais igualitária dentro da esfera pública.

Espera-se que o trabalho contribua para a discussão acerca das capacidades estatais, no contexto da descentralização no estado brasileiro e suas implicações sobre as políticas públicas, de forma a trazer o município para esta discussão, posto que, muitas vezes, esquecido pelos trabalhos que têm sido desenvolvidos no Brasil. Sugere-se que essa agenda de pesquisa seja ampliada em termos teóricos e empíricos, com o desenvolvimento de pesquisas que visem clarificar os desafios à capacidade dos municípios na gestão de políticas sociais no federalismo brasileiro.

\section{Referências}

ABRANCHES, Sérgio Henrique; SANTOS, Wanderley Guilherme dos; COIMBRA, Marcos Antônio. Política social e combate à pobreza. 4. ed. Rio de Janeiro: Jorge Zahar Editor, 1998.

ALCANTARA, Valderi de Castro; PEREIRA, José Roberto; SILVA, Érica Aline Ferreira. A formação de esferas públicas e a gestão social no Brasil: uma leitura a partir dos movimentos sociais (junho e julho - 2013). In: ENCONTRO NACIONAL DE PESQUISADORES EM GESTÃO SOCIAL, 8., 2014. Cachoeira, BA. Anais.. Cachoeira, BA: UFRB, 2104. Disponível em: <http//anaisenapegs.com.br/2014/dmdocuments/2891. pdf >. Acesso em: 07 dez. 2014.

ANDRADE, Daniela Meirelles:, CASTRO, Carolina Lescura de Carvalho; PEREIRA, José Roberto. Cidadania ou "estadania” na gestão pública brasileira? Revista de Administração Pública, Rio de Janeiro, v. 46, n. 1, p. 177-190, jan./fev. 2012. Acesso em: 05 dez. 2014. http://dx.doi.org/10.1590/S0034-76122012000100009.

ANDRADE, Silvério Antônio Moita de. O novo pacto federativo brasileiro e seu efeito na prestação dos serviços públicos: enfoque na segurança pública. Revista de Administração Pública, Rio de Janeiro, v. 38, n. 6, p. 1123-1137, nov./dez. 2004.

ANTINARELLI, Mônica Ellen Pinto Bezerra. Federalismo, autonomia municipal e a constitucionalização simbólica: uma análise da dependência financeira dos pequenos municípios mineiros. Revista da Faculdade de Direito da UFMG, Belo Horizonte, n. 61, p. 445-472, jul./dez. 2012.

ARRETCHE, Marta. Estado federativo e políticas sociais: determinantes da descentralização. Rio de Janeiro: Renavan, 2000.

Federalismo e igualdade territorial: uma contradição em termos? Dados, Rio de Janeiro, v. 53, n. 3 , p. 587-620, 2010.

Federalismo e políticas públicas sociais no Brasil: problemas de coordenação e autonomia. São Paulo em Perspectiva, São Paulo, v. 18, n. 2, p. 17-26, 2004. 
BENTO, Leonardo Valles. Governança e governabilidade na reforma do estado: entre eficiência e democratização. Barueri: Manole, 2003.

BICHIR, Renata Mirandola. Mecanismos federais de coordenação de políticas sociais e capacidades institucionais locais: o caso do Programa Bolsa Família. 2011. 271 f. Tese (Doutorado em Ciência Política) - Instituto de Estudos Sociais e Políticos, Universidade do Estado do Rio de Janeiro, Rio de Janeiro, 2011.

BOSCHI, Renato Raúl; GAITÁN, Flávio. Brasil e os atores emergentes em perspectiva comparada: capacidades estatais e a dimensão político-institucional. Brasília, 2012. Disponível em: <http://www.cdes.gov.br/evento/8869/ participacao-do-cdes-no-workshop-capacidades-estatais-para-o-desenvolvimento-vantagens-institucionaiscomparativas-em-paises-emergentes.html >.Acesso em: 12 dez. 2015.

BRASIL. Constituição (1988). Constituição da República Federativa do Brasil. 29. ed. atual. ampl. São Paulo: Saraiva, 2002.

BRESSER-PEREIRA, Luiz Carlos. A construção política do estado. Lua Nova, São Paulo, v. 81, p. 117-146, 2010.

CAMPANTE, Rubens Goyatá. O patrimonialismo em Faoro e Weber e a sociologia brasileira. Dados, Rio de Janeiro, v. 46, n. 1, p. 153-193, 2003. Disponível em:<http://www.scielo.br/scielo.php?script=sci_arttext\&pid=S0011$52582003000100005 \& \operatorname{lng}=$ en\&nrm=iso $>$. Acesso em: 25 nov. 2015.

CANÇADO, Airton Cardoso; PEREIRA, José Roberto;TENÓRIO, Guilherme. Gestão social: epistemologia de um paradigma. Curitiba: CRV, 2013.216 p.

CARVALHO, José Murilo de. Cidadania no Brasil: o longo caminho. 9. ed. Rio de Janeiro: Civilização Brasileira, 2007.

CHUBB, John; PETERSON, Paul (Ed.). Can the government govern? Washington:The

Brookings Institution, 1989.

CINGOLANI, Luciana. The state of state capacity: a review of concepts, evidence and measures. Maastricht: UNOMERIT, 2013.57 p. (Série de documentos de trabalhos, n. 53).

CÔRTES, Soraya Vargas. Viabilizando a participação em Conselhos de Política Pública Municipais: arcabouço institucional, organização do movimento popular e policy communities. In:HOCHMAN, Gilberto;ARRETCHE, Marta; MARQUES, Eduardo (Org.). Políticas públicas no Brasil. 3. ed. reimp. Rio de Janeiro: Fiocruz: 2007. cap. 4, p. 125-144.

DENHARDT, Robert. Teorias da administração pública. São Paulo: Cengage Learning, 2012.

EVANS, Peter. The capability enhancing developmental state: concepts and national trajectories. Rio de Janeiro: CEDE, 2011. (Texto para discussão, n. 3).

; RUESCHEMEYER, Dietrich; SKOCPOL, Theda. Bringing the state

back in. New York: Cambridge University Press, 1985.

FAORO, Raymundo. Os donos do poder: formação do patronato político brasileiro. v. 2. São Paulo: Globo, 2000.

GEDDES, Barbara. Politician's dilemma: building state capacity in Latin America. Berkeley:

University of California Press, 1994.

GOMES, Sandra. The multi-faceted debate on decentralization and collective welfare. Brazilian Political Science Review, Rio de Janeiro, v. 4, n. 2, p. 103-128, 2010. Disponível em: <http://socialsciences.scielo.org/scielo. php?script $=$ sci_arttext\&lng $=$ pt\&nrm $=$ iso\&tlng $=$ pt\&pid $=S 1981-38212010000100010>$. Acesso em: 21 mar. 2015.

GOMEZ, Ruben D. Gestión de políticas públicas: aspectos operativos. Revista Facultad Nacional Salud Pública, Medellin, v. 30, n. 2, p. 223-236, maio/ago. 2012.

GOMIDE,Alexandre de Ávila.; PIRES, Roberto Rocha C. Capacidades estatais e democracia: arranjos institucionais de políticas públicas. Brasília: IPEA, 2014. 
; SILVA F. S. E.; PIRES, R. R. C. Capacidades estatais e políticas públicas: passado, presente e futuro da ação governamental para o desenvolvimento. In: MONASTERIO, L. M.; NERI, M. C.; SOARES, S. S. D. (Ed.). Brasil em desenvolvimento 2014: estado, planejamento e políticas. Brasília: IPEA, 2014. v. 2, cap. 10, p. 231-246. (Brasil: o Estado de uma Nação).

GRINDLE, Merilee. Getting good government: capacity building in the public sectors of developing countries. Boston: Harvard University Press, 1997.

IIZUKA, Edson Sadao. O fluxo de ações e o processo decisório na política pública local: um estudo de caso na creche noturna em Laranjal Paulista-SP. Pensamento \& Realidade, São Paulo, v. 28, n. 1, p. 103-123, 2013.

INSTITUTO SUL-AMERICANO DE POLÍTICA E ESTRATÉGIA (ISAPE). Capacidade estatal: democracia e poder na era digital. Debate, n. 3, nov. 2012. Disponível em: <www.isape.org.br/index.php/publicacao/ download/115>. Acesso em: 03 nov. 2015.

JUNQUEIRA L.A. P. A gestão intersetorial das políticas sociais e o terceiro setor. Saúde e Sociedade, São Paulo, v. 13, n. 1, p. 25-36, jan./abr. 2004.

LOBATO, Lenaura. Algumas considerações sobre a representação de interesses no processo de formulação de políticas públicas. In: SARAIVA, E.; FERRAREZI, E. (Org.). Políticas públicas: introdução á teoria da política púbica. Brasília: ENAP, 2006. v. 1, cap. 4, p. 289-309.

LOTTA, Gabriela Spanghero; GONÇALVES, Renata; BITELMAN, Marina. A Coordenação federativa de políticas públicas: uma análise das políticas brasileiras nas últimas décadas. Cadernos Gestão Pública e Cidadania, São Paulo, v. 19, n. 64, p. 2-18, jan./jun. 2014.

LOUREIRO, Maria Rita; MACÁRIO,Vinícius; GUERRA, Pedro H. Democracia, arenas decisórias e políticas públicas: o Programa Minha Casa MinhaVida. In: GOMIDE,A.A.; PIRES, R. R. C. Capacidades estatais e democracia: arranjos institucionais de políticas públicas. Brasília: IPEA, 2014. p. 113-136.

MANN, Michael. The autonomous power of the state: its origins, mechanisms and results.

European Journal of Sociology, v. 25, n. 2, p. 185-213, 1984.

OLIVEIRA, José Antônio Puppim de. Desafios do planejamento em políticas públicas: diferentes visões e práticas. Revista de Administração Pública, Rio de Janeiro, v. 40, n. 1, p. 273-288, mar./abr. 2006.

PAES DE PAULA, Ana Paula. Administração pública brasileira entre o gerencialismo e a gestão social. Revista de Administração Pública, São Paulo, v. 45, n. 1, p. 36-49, jan./mar. 2005.

PIERSON, Paul. Fragmented welfare states: federal institutions and the development of social policy. Governance: an International Journal of Policy and Administration, Hoboken, v. 8, n. 4, p. 449-478, out. 1995.

PRUD'HOMME, Rêmy. The dangers of decentralization. World Bank Observer, Oxford, v. 10, n. 2, p. 201-220, ago.1995.

RODRIGUES, Gilmar. Democracia e partidos políticos: os gastos públicos municipais como instrumento de análise político-ideológica. In: HOCHMAN, Gilberto; ARRETCHE, Marta; MARQUES, Eduardo (Org.). Políticas públicas no Brasil. 3. reimp. Rio de Janeiro: Fiocruz: 2007. p. 275-299.

SKOCPOL, Theda. States and social revolutions: a comparative analysis of France, Russia, and China. New York: Cambridge University Press, 1979.

SOUZA, Celina de. Capacidade burocrática no Brasil e na Argentina: quando a política faz a diferença. Brasília: IPEA, 2015. (Texto para discussão, n. 2035).

Estado da arte da pesquisa em políticas públicas. In: HOCHMAN, G.; ARRETCHE, M.; MARQUES, E. (Org.). Políticas públicas no Brasil. 3. ed. reimp. Rio de Janeiro: Fiocruz: 2007. p. 65-86.

. Governos locais e gestão de políticas sociais universais. São Paulo em Perspectiva, São Paulo, v. 18, n. 2, p. 27-41, jun. 2004.

Políticas públicas: uma revisão de literatura. Sociologias, Porto Alegre, v. 8, n. 16, p. 20-45, jul./dez. 2006. 
. Modernização e democratização do estado: gestão e ações integradas de promoção e garantia de direitos. Belo Horizonte: UFMG-Cedeplar, 2010. 41 p. Relatório de Pesquisa. Disponível em: <https://www.cedeplar.ufmg. br/pesquisas/pis/Estudo\%2003.pdf.>. Acesso em: 15 dez. 2015.

Reinventando o poder local: limites e possibilidades do federalismo e da descentralização. São Paulo em Perspectiva, São Paulo, v. 10, n. 3, p. 103-112, 1996.

; Carvalho, Inaiá M. de. Reforma do estado, descentralização e desigualdades. Lua Nova, São Paulo, n. 48, p. 187-213, 1999.

STEIN, Guilherme de Queiroz. Q. Capacidades estatais e políticas públicas: análise das políticas industriais brasileiras no século XXI. In: SEMINÁRIO INTERNACIONAL DE CIÊNCIA POLÍTICA, 1., 2015, Porto Alegre. Anais... Porto Alegre: UFRGS, 2015. p. 79-104. Disponível em: <https://www.ufrgs.br/sicp/wpcontent/uploads/2015/09/Stein_Capacidades-Estatais-e-Pol\%C3\%ADticas-P\%C3\%BAblicas_SICP_2015-1. pdf.>. Acesso em: 23 out. 2015.

TILLY, Charles. As sociology meets history. New York: Academic Press, 1981.

THOMAZ, Andreane Rocha; CUNHA, Bruno Sales Trindade da. Análise das competências constitucionais em face da distribuição dos recursos entre entes federados e a necessidade de revisão do pacto federativo. Revista Brasileira de Direito Municipal, Belo Horizonte, v. 15, n. 51, p. 29- 44, jan./mar. 2014. 


\title{
State capacity and formulation of social policies by municipalities from the perspective of democratic public management
}

\begin{abstract}
The Federal Constitution of 1988 extended the responsibilities of the Brazilian Democratic State by establishing citizen-friendly activities in terms of social rights, which are implemented through public policies. At the same time, it operated the municipalization of some universal social services and generated new institutions in local governance, as it distributed skills and recognized the autonomy of the municipalities, place of execution and public services provision and public policy development consistent with the needs of the local population. This paper aims to promote a theoretical discussion and bring focus to the studies on state capacities, proposing that they be adapted in order to apply to the municipalities, aiming to boost the capacity of formulation of their social policies, as well as to contribute to the discussions on state capacities at the local level, integrating, for that, the reference of democratic public management.
\end{abstract}

Keywords: state capacity, formulation, social politics, democratic public management, decentralization, Municipalization.

\section{Capacidad estatal y formulación de políticas sociales por municipios bajo la óptica de la gestión pública democrática}

\section{Resumen}

La Constitución Federal de 1988 amplió las responsabilidades del Estado Democrático Brasileño, al establecer actividades de servicios para los ciudadanos en términos de derechos sociales, que se concretizan a través de políticas públicas. Al mismo tiempo, se operó la municipalización de algunos servicios sociales universales y se crearon nuevas instituciones en el gobierno local, pues se distribuyeron capacidades y se reconoció la autonomía de los municipios, el lugar de ejecución y entrega de los servicios públicos y de elaboración de políticas públicas acordes con las necesidades de la población local. Este trabajo tiene el objetivo de suscitar una discusión teórica y traer a la luz los estudios sobre las disposiciones estatales, proponiendo que se adapten y se apliquen a los municipios, con el objetivo de impulsar la capacidad de formulación de sus políticas sociales, así como contribuir con las discusiones sobre disposiciones estatales a nivel local, integrando, para ello, el referencial de la gestión pública democrática.

Palabras clave: capacidad del estado, formulación, políticas sociales, gestión pública democrática, descentralización, Municipalización. 